\title{
Assessment of the Relationship between Pelvic Tilt and the Sacro-Femoral-Pubic Angle in Middle- Aged and Elderly Asian Individuals
}

\author{
Takanori Kitagawa, Yoichi Iizuka, Hiroki Kobayashi, Tokue Mieda, Daisuke Tsunoda, \\ Atsushi Yamamoto, Tsuyoshi Tajika, Haku Iizuka, Kenji Takagishi \\ Department of Orthopedic Surgery, Gunma University Graduate School of Medicine, Maebashi, Japan
}

\begin{abstract}
Study Design: Cross-sectional study.
Purpose: The purpose of this study was to evaluate the correlation between pelvic tilt (PT) and the sacro-femoral-pubic (SFP) angle, which is easier to identify than PT, in middle-aged and elderly Asian subjects from the general population.

Overview of Literature: Measuring PT is important in the diagnosis and treatment of adult spinal deformity. However, identifying femoral heads, which are necessary to determine PT, using sagittal radiographs is often difficult.

Methods: Standing coronal and sagittal pelvic radiographs of individuals aged more than 50 years were taken during a local medical examination. The subjects were divided into female, male, and total groups at the time of evaluation. Linear regression analysis was performed to investigate the relationship between PT and the SFP angle, which were obtained from the X-rays.

Results: The present study included 291 subjects. There were no statistically significant differences between the left and right SFP angles, and there was gender difference regarding the SFP angle. However, a gender difference was observed regarding PT. The correlation between PT and the SFP angle was substantiated in each group. Pearson's correlation coefficients between PT and the SFP angle in the total, female, and male groups were $0.696,0.853$, and 0.619 , respectively. In the linear regression analysis, PT was calculated as follows: PT=60.1-0.77×(SFP angle) in the total group, PT=62.8-0.80×(SFP angle) in the female group, and PT=51.5-0.64×(SFP angle) in the male group.

Conclusions: A significant correlation between PT and the SFP angle was observed in middle-aged and elderly Asian subjects from the general population.
\end{abstract}

Keywords: General population; Pelvis; Spine; Parameter

\section{Introduction}

The prevalence of adult spinal deformity (ASD) is expected to increase as the population ages [1-3]. ASD can cause pain and disability and can consequently affect the health- related quality of life (HRQOL) [4]. Spinopelvic parameters, including pelvic tilt (PT), are used in the diagnosis and treatment of ASD $[5,6]$. However, measuring PT is often difficult because the femoral heads often become unclear on sagittal radiographs, particularly full spine ra-

Received Feb 26, 2017; Revised Apr 4, 2017; Accepted Apr 18, 2017

Corresponding author: Takanori Kitagawa

Department of Orthopedic Surgery, Gunma University Graduate School of Medicine, 3-39-22 Showa, Maebashi, Gunma $371-8511$ Japan Tel: +81-27-220-8269, Fax: +81-27-220-8275, E-mail: m12702016@gunma-u.ac.jp 
diographs. In addition, evaluating the center of the femoral head on the opposite side in patients with bipolar or total hip arthroplasty may not be possible. Blondel et al. [7] reported a correlation between PT and the sacro-femoralpubic (SFP) angle, which is measured from coronal radiographs of the pelvis, and concluded that even if the femoral head is blurred in sagittal radiographs, it is possible to predict PT from the SFP angle. A correlation between PT and the SFP angle has been reported in different diseases and in subjects of various ages [8-11]. However, to date there are no reports on the association between PT and the SFP angle in middle-aged and elderly Asian individuals.

The purpose of the present study was to evaluate the correlation between PT and the SFP angle in middle-aged and elderly Asian subjects from the general population.

\section{Materials and Methods}

\section{Subjects}

Local medical examinations were conducted in a mountain village in Japan to prevent lifestyle-related diseases. During a local medical examination in 2015, residents older than 50 years of age underwent standing coronal and sagittal pelvic radiography. Radiographs of patients with advanced hip osteoarthritis were excluded because the exact border between the acetabuli and the center of the femoral head was unclear. Residents with bipolar or total hip arthroplasty were also excluded.

Consent was obtained from all subjects after informing

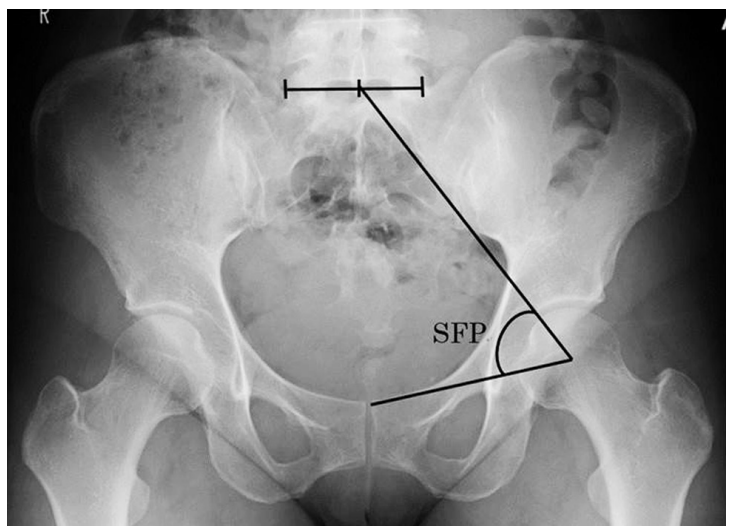

Fig. 1. The sacro-femoral-pubic (SFP) angle was defined as the angle between the midpoint of the upper sacral endplate (by drawing the midpoint between the lateral borders of the L5-S1 facet joints), the centroid of one acetabulum, and the upper midpoint of the pubic symphysis on a coronal radiograph. them that their data would be used in the present study.

This study was approved by the Institutional Review Board of Gunma University (IRB No. 23-31). All subjects provided written informed consent before participating in this study.

\section{Radiographic measurements}

The SFP angle was defined as the angle between the midpoint of the upper sacral endplate (by drawing the midpoint between the lateral borders of the L5-S1 facet joints), the centroid of one acetabulum, and the upper midpoint of the pubic symphysis on a coronal radiograph (Fig. 1) [7]. The SFP angle was measured on the right and left sides.

PT was defined as the angle between the lines connecting the midpoint of the sacral plate to the point halfway between the two femoral centers and the vertical plane on a sagittal radiograph (Fig. 2) [11].

\section{Statistical analysis}

Data were expressed as mean \pm standard deviation. Gender differences in the SFP angle, PT, and age and differences between the left and right SFP angles were evaluated

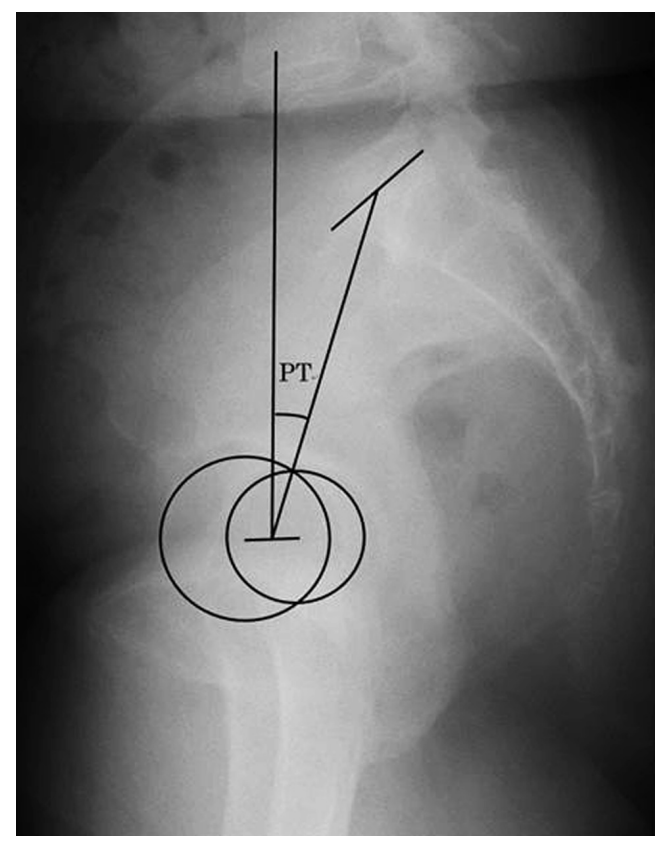

Fig. 2. Pelvic tilt (PT) was defined as the angle between the lines connecting the midpoint of the sacral plate to the point halfway between the two femoral centers and the vertical plane on a sagittal radiograph. 
by Welch's test. Pearson's correlation analysis and linear regression analysis were used to assess the relationship between PT and the SFP angle. A $p$-values of $<0.05$ were considered to indicate statistical significance. All statistical analyses were performed using the IBM SPSS Statistics software program (ver. 22; IBM Japan, Tokyo, Japan).

\section{Results}

\section{Demographics}

The present study included 291 subjects (193 females, 98

Table 1. Summary of the patients' characteristics

\begin{tabular}{lcc} 
Characteristic & Number & Age $(\mathrm{yr})$ \\
\hline Females & 193 & $68.5 \pm 9.9$ \\
\hline Males & 98 & $70.0 \pm 9.1$ \\
\hline Total & 291 & $69.0 \pm 9.6$ \\
\hline
\end{tabular}

The age of the male and female subjects did not differ to a statistically significant extent ( $p>0.05$, Welch test).

Table 2. The average PT and SFP angle of each group

\begin{tabular}{llll}
\multirow{2}{*}{ Group } & PT $\left({ }^{\circ}\right)$ & \multicolumn{2}{c}{ SFP angle $\left({ }^{\circ}\right)$} \\
\cline { 2 - 4 } Females & $20.0 \pm 10.7$ & $53.6 \pm 11.5$ & $53.2 \pm 11.6$ \\
Males & $16.4 \pm 6.9$ & $52.6 \pm 7.1$ & $52.3 \pm 7.4$ \\
Total & $18.8 \pm 9.7$ & $53.3 \pm 10.2$ & $52.9 \pm 10.4$ \\
\hline
\end{tabular}

No statistically significant difference was observed between the left and right SFP angles ( $p>0.05$, Welch test). No gender difference was observed in the SFP angle ( $p>0.05$, Welch test). A gender difference was observed in the PT ( $p<0.05$, Welch test).

PT, pelvic tilt; SFP, sacro-femoral-pubic. males). The mean age of the subjects in the total, female, and male groups were $69.0 \pm 9.6,68.5 \pm 9.9$, and $70.0 \pm 9.1$ years, respectively. The ages of the male and female subjects were not significantly different (Table 1).

\section{Radiographic results}

PT and the SFP angle of the subjects are shown in Table 2. In the total group, the average PT, right-side SFP angle, and left-side SFP angle were $18.8^{\circ} \pm 9.7^{\circ}, 53.3^{\circ} \pm 10.2^{\circ}$, and $52.9^{\circ} \pm 10.4^{\circ}$, respectively. In the female group, the average PT, right-side SFP angle, and left-side SFP angle were $20.0^{\circ} \pm 10.7^{\circ}, 53.6^{\circ} \pm 11.5^{\circ}$, and $53.2^{\circ} \pm 11.6^{\circ}$, respectively. In the male group, the average right-side SFP angle and leftside SFP angle were $16.4^{\circ} \pm 6.9^{\circ}, 52.6^{\circ} \pm 7.1^{\circ}$, and $52.3^{\circ} \pm 7.4^{\circ}$, respectively. No statistically significant differences were observed in the SFP angles on the left and right sides $(p>0.05)$. Moreover, there was no gender difference regarding the SFP angle; however, a gender difference was observed regarding PT.

\section{Correlation analysis and linear models}

According to the results of Pearson's correlation analysis, there was a strong correlation between PT and the

Table 3. A summary of the Pearson's correlation coefficients of each group

\begin{tabular}{lc} 
Group & Pearson coefficient \\
Females & 0.853 \\
Males & 0.619 \\
Total & 0.696 \\
\hline
\end{tabular}
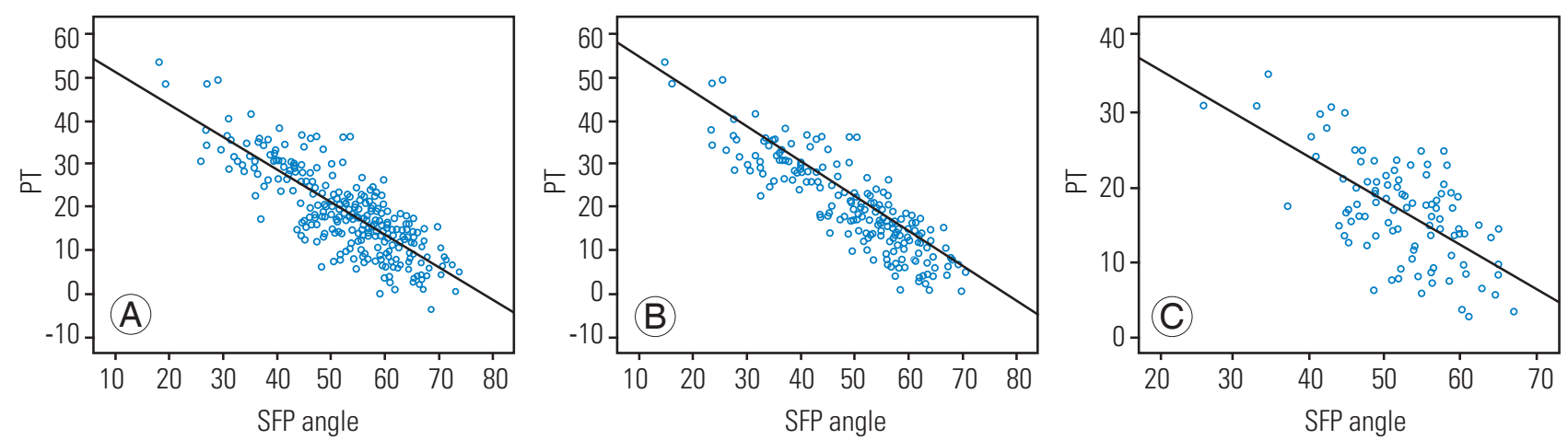

Fig. 3. (A) Linear regression model showing the correlation between pelvic tilt (PT) and the sacro-femoral-pubic (SFP) angle in the total group. (B) Linear regression model showing the correlation between PT and the SFP angle in the female group. (C) Linear regression model showing the correlation between PT and the SFP angle in the male group. 
SFP angle. Pearson's correlation coefficients in the total, female, and male groups were $-0.696,-0.853$, and -0.619 , respectively (Table 3 ). Linear regression analysis was performed in which PT was calculated as follows: $\mathrm{PT}=60.1-0.77 \times(\mathrm{SFP}$ angle $)$ in the total group, $\mathrm{PT}=62.8-0.80 \times($ SFP angle $)$ in the female group, and $\mathrm{PT}=51.5-0.64 \times($ SFP angle $)$ in the male group (Fig. 3$)$.

\section{Discussion}

ASD is likely to cause pain, disability, and a reduction in the HRQOL [4]. Recent studies have used the Scoliosis Research Society (SRS)-Schwab Adult Spinal Deformity classification in the diagnosis and treatment of ASD $[4,12]$. PT is included as one of the three sagittal modifiers in this classification system. PT is correlated with the HRQOL in ASD and is one of the critical parameters when planning realignment surgery for ASD [6]. Measuring PT is therefore very important. However, the profile of the femoral heads is often blurred in sagittal radiographs of the full spine, making it difficult to measure PT.

Blondel et al. [7] showed that the SFP angle obtained from coronal radiographs of the pelvis correlated with PT and suggested the formula PT $=74.6-0.942 \times($ SFP angle $)$. Following this report, other authors have demonstrated a correlation between PT and the SFP angle, although these authors focused on different diseases and patients of different ages [8-11]. Our formula differs from the formulae reported to date with regard to the intercept and slope. These factors might be affected by a difference in the spinal disease, race, or age. In almost all reported studies, subjects had no spinal disease or a spinal disease such as adolescent idiopathic scoliosis, ankylosing spondylitis, or congenital scoliosis. Because we only observed pelvic radiographs in local medical examinations, it was not possible to confirm the presence or absence of spinal diseases. $\mathrm{Hu}$ et al. [9] derived their formula by studying patients with ankylosing spondylitis and showed fewer errors when they compared their formula with that reported by Blondel et al. in their patients. Consequently, appropriate formulae for calculating the relationship between PT and the SFP angle may differ in other diseases. Additionally, some authors have noted that racial differences influence the parameters of the spine and/or pelvis [13-17]. MacThiong et al. [17] reported that weak correlations existed between PT and the sacral slope (SS) with respect to age. As the average age of our subjects was the oldest among the studies that investigated the relationship between PT and the SFP angle, it is possible that the differences between the formulae in the present and previous studies are explained not only by racial differences but also by age differences.

In the present study, a gender difference was observed regarding PT. It is possible that this affected the intercept and slope of the formula. Consequently, it is necessary to separately derive PT for each gender.

Various parameters by which PT can be estimated have been reported [18-22]. Tannast et al. [23] verified the reliability of these parameters. In females and males, the vertical distance between the upper edge of the pubic symphysis and the midpoint of the sacrococcygeal joint showed the strongest correlation among all other parameters (Pearson's correlation coefficient: 0.63 in females, 0.68 in males). However, numerous studies have examined the relationship between PT and the SFP angle [8-11,24]. Our results also support the use of the SFP angle in the prediction of PT.

Sagittal modifiers in the SRS-Schwab Adult Spinal Deformity classification include pelvic incidence (PI) minus lumbar lordosis (LL), sagittal vertical axis (SVA), and PT. Because the upper sacral endplate is visible in the sagittal radiographs of the full spine, LL, SVA, and SS can be measured. If PT can be predicted from the SFP angle, it is possible to estimate PI using the following formula: $\mathrm{PI}=\mathrm{PT}+\mathrm{SS}$.

PT is known to change in the supine and standing positions [25]. Dislocation in cases of total hip arthroplasty depends on the anteversion of the cup. Measuring the change in PT (using the formula) can help in planning the insertion of implants during surgery. As a result, it may reduce the risk of dislocation. However, in such cases, it is necessary for the other side of the hip joint to be normal.

The present study has some limitations. First, the size of the male cohort was relatively small. It is conceivable that the accuracy could have been improved by taking pelvic radiographs of other regions. Second, we were unable to perform radiography of the spine, which would have allowed us to obtain useful information regarding PT and the SFP angle. Consequently, we could not investigate the relationship of other spinal parameters, including LL and sagittal SVA, with the SFP angle. However, to the best of our knowledge, this is the first report to show a correlation between PT and the SFP angle in middle-aged and elderly Asian subjects from the general population. More- 
over, to date, the number of subjects in the present study is the highest. Consequently, we believe that our formula is considerably helpful for decision-making in the treatment of patients with ASD and hip disorders.

\section{Conclusions}

A significant correlation was observed between PT and the SFP angle in middle-aged and elderly Asian subjects from the general population.

\section{Conflict of Interest}

No potential conflict of interest relevant to this article was reported.

\section{References}

1. Fehlings MG, Tetreault L, Nater A, et al. The aging of the global population: the changing epidemiology of disease and spinal disorders. Neurosurgery 2015;77 Suppl 4:S1-5.

2. O'Lynnger TM, Zuckerman SL, Morone PJ, Dewan MC, Vasquez-Castellanos RA, Cheng JS. Trends for spine surgery for the elderly: implications for access to Healthcare in North America. Neurosurgery 2015;77 Suppl 4:S136-41.

3. Iizuka Y, Iizuka H, Mieda T, Tajika T, Yamamoto A, Takagishi K. Epidemiology and associated radiographic spinopelvic parameters of symptomatic degenerative lumbar scoliosis: are radiographic spinopelvic parameters associated with the presence of symptoms or decreased quality of life in degenerative lumbar scoliosis? Eur Spine J 2016;25:2514-9.

4. Terran J, Schwab F, Shaffrey CI, et al. The SRSSchwab adult spinal deformity classification: assessment and clinical correlations based on a prospective operative and nonoperative cohort. Neurosurgery 2013;73:559-68.

5. Lafage V, Schwab F, Patel A, Hawkinson N, Farcy JP. Pelvic tilt and truncal inclination: two key radiographic parameters in the setting of adults with spinal deformity. Spine (Phila Pa 1976) 2009;34:E599606.

6. Schwab F, Patel A, Ungar B, Farcy JP, Lafage V. Adult spinal deformity-postoperative standing imbalance: how much can you tolerate? An overview of key pa- rameters in assessing alignment and planning corrective surgery. Spine (Phila Pa 1976) 2010;35:2224-31.

7. Blondel B, Schwab F, Patel A, et al. Sacro-femoralpubic angle: a coronal parameter to estimate pelvic tilt. Eur Spine J 2012;21:719-24.

8. Bao H, Liu Z, Zhu F, et al. Is the sacro-femoralpubic angle predictive for pelvic tilt in adolescent idiopathic scoliosis patients? J Spinal Disord Tech 2014;27:E176-80.

9. Hu J, Ji ML, Qian BP, et al. Can pelvic tilt be predicated by the sacrofemoral-pubic angel in patients with thoracolumbar kyphosis secondary to ankylosing spondylitis? Spine (Phila Pa 1976) 2014;39:E1347-52.

10. Liu Z, Bao H, Qiu Y, et al. Evaluation of demographic factors affecting predictability of the sacrofemoral-pubic angle in healthy adolescents. J Anat 2015;226:163-8.

11. Ghandhari H, Fouladi DF, Safari MB, Ameri E. Correlation between pelvic tilt and the sacro-femoralpubic angle in patients with adolescent idiopathic scoliosis, patients with congenital scoliosis, and healthy individuals. Eur Spine J 2016;25:394-400.

12. Schwab F, Ungar B, Blondel B, et al. Scoliosis Research Society-Schwab adult spinal deformity classification: a validation study. Spine (Phila Pa 1976) 2012;37:1077-82.

13. Lonner BS, Auerbach JD, Sponseller P, Rajadhyaksha AD, Newton PO. Variations in pelvic and other sagittal spinal parameters as a function of race in adolescent idiopathic scoliosis. Spine (Phila Pa 1976) 2010;35:E374-7.

14. Zarate-Kalfopulos B, Romero-Vargas S, OteroCamara E, Correa VC, Reyes-Sanchez A. Differences in pelvic parameters among Mexican, Caucasian, and Asian populations. J Neurosurg Spine 2012;16:516-9.

15. Yong Q, Zhen L, Zezhang Z, et al. Comparison of sagittal spinopelvic alignment in Chinese adolescents with and without idiopathic thoracic scoliosis. Spine (Phila Pa 1976) 2012;37:E714-20.

16. Zhu Z, Xu L, Zhu F, et al. Sagittal alignment of spine and pelvis in asymptomatic adults: norms in Chinese populations. Spine (Phila Pa 1976) 2014;39:E1-6.

17. Mac-Thiong JM, Roussouly P, Berthonnaud E, Guigui P. Age- and sex-related variations in sagittal sacropelvic morphology and balance in asymptomatic adults. Eur Spine J 2011;20 Suppl 5:572-7.

18. Katada S, Ando K. A rontgenographic evaluation of 
the indices for hip dysplasia in children influenced by pelvic tilt. In: Ueno R, Akamatsu N, Itami Y, et al., editors. The hip: clinical studies and basic research. Amsterdam: Excerpta Medica; 1984. p.137-40.

19. Thoren B, Sahlstedt B. Influence of pelvic position on radiographic measurements of the prosthetic acetabular component. An experimental study on a pelvic model. Acta Radiol 1990;31:133-6.

20. Kojima A, Nakagawa T, Tohkura A. Simulation of acetabular coverage of femoral head using anteroposterior pelvic radiographs. Arch Orthop Trauma Surg 1998;117:330-6.

21. Nishihara S, Sugano N, Nishii T, Ohzono K, Yoshikawa $\mathrm{H}$. Measurements of pelvic flexion angle using three-dimensional computed tomography. Clin Orthop Relat Res 2003;(411):140-51.
22. Siebenrock KA, Kalbermatten DF, Ganz R. Effect of pelvic tilt on acetabular retroversion: a study of pelves from cadavers. Clin Orthop Relat Res 2003;(407):241-8.

23. Tannast M, Murphy SB, Langlotz F, Anderson SE, Siebenrock KA. Estimation of pelvic tilt on anteroposterior X-rays: a comparison of six parameters. Skeletal Radiol 2006;35:149-55.

24. Raux S, Abelin-Genevois K, Blondel B, Mancini J, Jouve JL. Estimation of sagittal pelvic orientation from frontal standard radiograph using the sacralfemoral-pubic angle: feasibility study in the pediatric population. Eur Spine J 2015;24:1143-7.

25. Pullen WM, Henebry A, Gaskill T. Variability of acetabular coverage between supine and weightbearing pelvic radiographs. Am J Sports Med 2014;42:2643-8. 